\title{
Accessing knowledge through narrative context
}

\author{
Giuliana Dettori ${ }^{1}$ and Francesca Morselli ${ }^{2}$ \\ ${ }^{1}$ ITD CNR, Via De Marini 6, 16149 Genova, Italy \\ dettori@itd.cnr.it \\ http://www.itd.cnr.it/personalescheda.php?Id=12 \\ 2 Dipartimento di matematica, Università di Genova, Via Dodecaneso 35, \\ 16146 Genova, Italy \\ morselli@dima.unige.it, \\ http://www.dima.unige.it/ morselli
}

\begin{abstract}
In this paper we discuss how narrative may contribute to create meaningful learning contexts. Starting from a socio-constructivist and situated learning perspective, we acknowledge the crucial role of context in accessing knowledge. Then we point out the potential of narrative in education and discuss the positive role it can play in the creation of meaningful learning contexts. To this end, we focus on different examples of narrative contexts within technology-enhanced learning environments, drawn from the literature. We analyze what kind of contexts raise from different ways to set up narrative activities. Our study points out that narrative can be a powerful tool for the creation of a variety of contexts suitable for different learning situations, by stimulating learners' direct involvement and offering a concrete starting point for reflection.
\end{abstract}

\section{Introduction}

What is context? This term is widely used, in different ways and for different purposes, in many research fields somehow related with accessing knowledge, such as philosophy, linguistics, psychology, education, cognitive science, problem solving, theory of communication and artificial intelligence. Its definition can range from "a set of features in the world" to "a set of assumptions on the world", hence viewing it as an objective state of affairs, on one side, or as a subjective representation of the world, on the other side [14], or any combination of these two extreme positions, based on the underlying reference theory and on the application at hand.

In order to restrict and better focus our analysis, we will concentrate on the educational field, where context is increasingly attributed a major role. Here, under 
the influence of social constructivism and situated cognition theories, learning is widely considered as a context-dependent activity [3] that takes place by interacting with content and context. Content is the information to be learnt, while context is the set of all circumstances that are relevant for the learner to build his/her knowledge. According to socio-constructivism, content and context are dual elements interwoven with each other: "context holds in itself the seed of content and content holds in itself the seed of context" [11].

The connection among content and context is even more emphasized in situated learning, where knowledge is seen as characterized by the situation (or context) within which it is constructed, which includes physical, emotional, intellectual, social and cultural aspects of the learning environment [12]. In this view, which includes both external, objective elements and subjective, cognitive ones, context is also influenced by the behavior and past experiences of the learner him/herself [13]. Therefore, it appears important to plan activities for the learners that could allow them to take part in shaping learning contexts that suit their needs and attitudes.

In this paper, we argue that narrative can be a good tool to create learning contexts that deeply involve the learners. We focus in particular on narrative contexts within technology-enhanced learning environments, i.e., contexts which are heavily determined by stories and narrations related to the learning task, and take advantage of some technological means to facilitate the creation of narrative or amplify its effect. To this end, we analyze several examples of narrative contexts, discussing their potential role and value.

\section{Learning potential of narrative}

Narrative is increasingly used in education, since it has been recognized as a natural expressive form for people of any age and culture [4], as well as a privileged way to help develop cognitive abilities and organize knowledge [17]. It is a form of meaning making where human beings engage in symbolic activities to construct and make sense of themselves and work out a coherent meaning for their experiences [6].

The roots of this rich cognitive potential clearly appear in the definition that Bruner [4, p. 43] gives of narrative: “... a unique sequence of events, mental states, happenings ... But these constituents do not have a life or meaning of their own. Their meaning is given by their place in the overall configuration of the sequence as a whole...". This definition, which is in agreement with the definitions of narrative given by scientists with different focus and orientation [8], highlights the presence of logical constraints among the elements of a story: all elements contribute to form a whole which, in turn, gives meaning to each single part [6]. This allows people to understand more than it is explicitly reported, and hence leads both producers and receivers of a narrative to access knowledge by carrying out a meaning construction process.

This applies to both invented narratives (stories) and true ones (history and experience narrations), as pointed out by Ricoeur [15, p. 288], who recognizes " $a$ family resemblance at the level of sense or structure between these two narrative types". 
The literature highlights that narrative's positive influence on learning concerns not only cognition, but also motivation and emotions. As Bruner [6] points out, "narrative in all its forms is a dialectic between what was expected and what came to pass" (p.15), as well as "an invitation to problem finding, not a lesson in problem solving" (pg. 20). For this reason, the use of narrative in learning can result challenging and stimulate curiosity and fantasy, which are major components of intrinsic motivation, according to the taxonomy proposed by Malone and Leppers [16]. The support to emotions raises from the fact that stories are based on an interplay between characters and causation [2], which leads the user to highlight aspects of personality, emotional state and social standing, as well as the motives and intentions which underlie the characters' actions.

The context-making potential of narrative is also underlined in the literature. Arnold, Smith \& Trainer [1], for instance, argue that narrative can help make more visible the context of individuals and is an important way of revealing and negotiating contexts in virtual settings.

We add that narrative can help creating meaningful learning contexts by offering a simple way to connect context knowledge and external setting with the learner's experience and by supporting his/her engagement in a deep meaning-making process. This is due to several reasons:

- Narrative always has a narrator, hence it is always told from an explicitly declared perspective, which can help people get aware of the plurality of possible points of view and information sources.

- Narrative, including (implicit and explicit) logical constraints among the narration elements, stimulates the users (be they narrating or receiving a story) to make inferences and deductions, and hence to become aware to "know more than they thought" [6].

- Narrative concerns actions and events, which are something concrete and hence can constitute solid, objective ground for discussion and reflection.

- Sharing stories is traditionally a social activity, hence narrative is particularly suitable to create social contexts; this is important from the point of view of learning, in that "the cultural contexts that favor mental development are principally and inevitably interpersonal" [5, p. 68].

In the next sections, we support our claim by describing some narrative contexts that appear particularly interesting, and by discussing their characteristics and potential.

\section{Examples of narrative learning contexts}

Stories can be used in different ways, within technology-enhanced learning environments, to shape a context apt to facilitate learning, as illustrated by the following examples, drawn from the literature.

\subsection{Creating context by role-playing}

Revolution (by The Education Arcade, http://www.educationarcade.org/revolution) is a multi-user, role-play, educational game on the American Revolution, to be 
played in 45-minute sessions in a networked environment. The users take the roles of seven different kinds of characters (such as upper class lawyer, patriotic craftman, or African American house slave) who formed the society of the American colonies at the time of the Revolution. Starting from a background story, chosen among a number of available ones that refer to historical facts, and from general guidelines on characters' behaviours (which include compliance with the social rules of the period), participants create always new stories by means of their actions (i.e., conversations with other characters and execution of professional activities). The environment includes also some synthetic characters, whose function is to guide the role-players, by means of suitable conversations, to respect historical and semantic constraints. Experiencing different roles, the learners are led to focus on the life in the considered historical period from different social, economic and cultural perspectives, hence deepening understanding of the historical facts which are object of study.

In this educational game, the story construction by participants' actions provides a context for the intended historical learning. Taking a role, each player becomes part of the unfolding narrative actions, which can positively influence understanding and memorization, as well as support motivation to get interested in an event that would otherwise be far from the learners' life. The historical background constraining players' actions induces learning. Knowledge is built by interacting and discussing with peers. Like with all role-playing games, however, the activity must be carefully prepared in order to give rise to meaningful stories and actually favor the expected learning.

\subsection{Creating context by taking part in a given story}

Crystal Island [16] is an environment for middle-school students, supporting inquirybased learning in microbiology and genetics, to be played individually. The user is led to engage in a problem solving activity by taking part in a given story: he/she is travelling in a far country with a scientific expedition which is decimated by an epidemic disease; in order to stop it and save the expedition, a genetic problem needs to be solved. The learner navigates the environment and, interacting with a number of synthetic, semi-autonomous characters, gets information on the topic of study and suggestions to work out a solution. The fact that the characters are implemented by means of semi-autonomous agents implies that they behave in a (partially) new way every time they interact with the user, so that the user can repeatedly interact with the same character without passing through the same conversation again and again, as it would be the case with simple multimedia environments.

The background story provided creates a context for the assigned task and helps the user to make sense of the data. It works as a container to highlight the different kinds of elements to take into consideration when solving microbiology and genetics problems, helping the learner to build an overall picture from a plurality of data and hence supporting a meaning-making process which is functional to the construction of a solution. Instead of simply being handed information, the student draws out meaning by interacting with the context. This data-highlighting role is not trivial nor irrelevant in relation to learning: some research studies underline that problem 
solving is more often hindered by an incomplete or inaccurate analysis of the data involved than by the lack of suitable solution strategies [18].

\subsection{Creating context by sharing reflective narrations}

In a regular face-to-face foreign language course at university level, one of the teachers sets up a blog and asks a group of volunteers from her course to narrate the language learning experience they are undergoing during the course. This activity usually lasts about 10 weeks and involves a limited number of students (6 to 10). The assignment is not to report reflections but actually to narrate one's own learning story as it is taking place during the course.

As a consequence, over the weeks, personal stories develop and intertwine in the blog, creating a social context in which learning is highlighted and becomes itself an object of study. Learning-related actions become visible (to each narrator and to her/his peers) and provoke reflection and reaction. Students have under their eyes, and can compare, difficulties, strategies and achievements, hence learning from each other and improving awareness of different ways of learning as well as of their own strengths and weaknesses as language learners.

\subsection{Creating context by sharing experience online}

LODE [7] is a virtual environment supporting teachers' collaborative work on Learning Objects (LOs). It allows users to share not only educational material in the form of LOs, but also personal views, experiences of use and reflections, by providing discussion spaces associated to each LO. It aims to help teachers learn from each other and to favour by this means teachers' professional growth, as well as the diffusion of innovation in the school. Among the discussion spaces associated to each LO, there is a "narrative corner" where teachers are invited to narrate their use experience with the associated LO.

The possibility to post and read such narrations creates a context for improving the use of LOs, giving concreteness to the shared materials and helping to make the pedagogical intention behind them clear. The presence of narrations by different teachers in relation to every single LO helps the users gain an articulated, multidimensional view of it, hence turning the re-use experience into a learning opportunity for all teachers involved, including the original producer of the material. Therefore, this narration sharing also creates a social context for teachers' learning from each other and professional growth. This base of personal stories of use constitutes a shared ground on which pedagogical reflection can develop. This task could not be done as effectively by sharing only reflections instead of personal stories, since reflections are filtered by personal judgement while stories, though including the narrator's point of view, are closer to raw data and can better allow prospective re-users to look at the material and related experiences from their own point of view. 


\subsection{Creating context by collective narration}

Dolk \& Den Hertog [10] describe a face-to-face training activity for Mathematics teachers they carry out in the Netherlands. In such activities, a small group of teachers firstly watches a video showing a classroom episode where some pupils are experiencing difficulty with solving a mathematical problem. The teachers are then asked to jointly produce a story of what they saw in the video before starting analyzing it. This task, which aims to improve observation and entails negotiation among the group participants, is much less trivial than one could think; as a matter of fact, experience highlights that teachers may need to see the movie several times before being able to make a precise, shared account of what happens in the movie. Precise observation, on the other hand, is a key skill for teachers, crucial to be able to correctly diagnose learning difficulties so as to be in condition to effectively help the students to overcome them.

The joint construction of stories from observed videos, as carried out in this example, creates a social context where the teachers involved can support each other in enhancing observation skills, and finally leads to a deeper understanding of the educational situations taken into consideration. Narrating before reflecting results more effective than only reflecting, in that it creates a shared view of the situation and gives rise to something concrete -the jointly reconstructed story- on which a meaningful reflection and discussion can develop, hence finally supporting professional development.

\section{Discussion and conclusion}

These five examples presented widely differ from each other as concerns the population involved, the expected learning and the ways narrative is used, as well as what context is created and in which way it influences learning.

As regards the target population, the examples address learners of different ages: middle school and university students as well as adult, in-service teachers. Moreover, it is easy to figure out to adapt each of the mentioned narrative activities to learners of different ages; De Vries [9], for example, describes a case of reflective narration carried out with primary school children in the framework of science classes. This fact suggests that narrative contexts can be suitable for a wide range of learners, independently of their age.

Also the knowledge to be learned varies from example to example, ranging from curricular topics (history in Revolution and biology in Crystal Island), to metacognition and self-regulated learning (in the Narrative blog), up to collaborative and teaching skills in the last two examples. Also in this case, it is reasonably possible to create analogous narrative contexts for other topics or to make use of similar narrative activities in different fields. This underlines that narrative activities have wide possibilities of applications.

An even wider difference can be noticed in the way narrative is used: in the first two examples, a background story is given, even though the learners contribute to shape more detailed stories starting from it, while in the last three examples the 
narrative is completely determined by the users. In the first group, the story is completed through the learners' actions, while in the second group, the narratives created are expressed in words. Inside these two groups, however, we notice again deep differences.

In Revolution, the background story is just sketched, giving the main lines of the situations that can be developed and assigning constraints for the possible behavior of the characters. A precise plot is not given, and the users create the actual story by means of their activity. In Crystal Island, on the other hand, the background story is much more developed; taking part in it, the user does not influence its expected conclusion (solving the proposed problem), but develops his/her own way to reach it. The plot in this case is given; only the way to develop it (sequence of interactions with the synthetic characters and the program's features) is determined by the user's behaviour. These different ways to use narrative are very much in line with the two cognitive tasks assigned. In Revolution, the need to generate the story puts into play creativity, which can likely be useful to explore the socio-political situation of the historical period of interest. Not having to create a story, on the contrary, gives freedom to Crystal Island's user to concentrate on data collection, organization and elaboration, which likely facilitates problem solving.

As concerns the contexts where a narrative is completely created by the learners, we notice a strong similarity between those in the Narrative blog and in the LODE environment, since in both cases a narration of experiences is produced. The aim, however, is different: in the first case it is to stimulate meta-reflection, while in the second it is to support learning from each other and a thoughtful re-use of LOs. The last example in this group, the Teacher Training, shows a strong similarity with storytelling, in that a story to be told is given in a video, and the assigned narrative activity stimulates careful observation and recognition of crucial points.

From the above discussion, however, it is clear that, beyond the differences pointed out, all the considered narrative contexts share a few important aspects:

- Stories constitute a starting point to boost reflection.

- The narrative activity that shapes the context is always strongly connected with the learning content.

- Learners actively take part in shaping the context through the narrative activity they carry out. This gives rise to learning contexts that are suited to the learners' characteristics and needs, and also treasure their experience.

Finally, we remark that in all examples technology does not appear essential, but is certainly very useful. For instance, as concerns Revolution, a similar role play could be carried out by traditional means, i.e., by writing a plot and performing it in class. The use of technology offers several advantages: backgrounds, characters and props are provided, lowering the production effort; synthetic characters control the historical consistence of stories without teacher's interventions, that could result intrusive and hinder creativity; giving life to virtual characters helps avoiding the embarrassment of playing in person. Analogously, the use of technology to share stories in the Narrative blog and in the "narrative corner" of LODE makes experience sharing easier than with traditional means, and facilitates recording for future reference. 


\section{References}

[1] Arnold, P., Smith, J. D. and Trayner, B. (2006). Narrative: Designing for Context in Virtual Settings. In: Figueiredo, A. D. \& Afonso A.P. eds., Managing Learning in Virtual Setting: the role of context (p. 197-218). Hershey PA: Information Science Publishing.

[2] Aylett, R. (2006). And they both lived happily ever after? In G. Dettori, T. Giannetti, A. Paiva \& A. Vaz (eds.), Technology-mediated narrative environments for learning (p. 525). Rotterdam: Sense Publishers.

[3] Blandin, B. (2006). The Role of Context When Implementing Learning Environments: Some Key Issues. In: Figueiredo, A. D. \& Afonso A.P. (eds.), Managing Learning in Virtual Setting: the role of context (p. 62-83). Hershey PA: Information Science Publishing.

[4] Bruner, J. (1990). Acts of meaning. Cambridge, MA: Harvard University Press.

[5] Bruner, J. (1996). The culture of Education. Cambridge, MA: Harvard University Press.

[6] Bruner, J. (2003). Making stories: law, literature, life. Cambridge, MA: Harvard University Press.

[7] Dettori G., Forcheri P. and Ierardi M.G. (2006) Endowing LOs with a Social Dimension, In Wenyin Liu, Qing Li and Rynson W.H. Lau (eds.), Advances in Web Based Learning (p. 189-202). Lecture Notes in Computer Science, 4181, Springer.

[8] Dettori, G. (2007). Towards a classification of Narrative Learning Environments. ITDCNR Report 05/07 (Genova, Italy), available at http://telearn.noe-kaleidoscope.org/openarchive/browse?resource $=1542$

[9] De Vries, B. (2006). Reflective narration with e-mail: Issues concerning its implementation. In G. Dettori, T. Giannetti, A. Paiva \& A. Vaz (eds.), Technologymediated narrative environments for learning (p. 41-54). Rotterdam: Sense Publishers.

[10] Dolk, M. and Den Hertog, J. (2006). Teachers' storied lives: narratives in teacher education, Proceedings NILE 2006, P. Brna ed., p. 13-26.

[11] Figueiredo, A.D. and Afonso, A.P. (2006). Context and Learning: A Philosophical Framework. In: Figueiredo, A. D. \& Afonso A.P. (eds.), Managing Learning in Virtual Setting: the role of context (p. 1-22). Hershey PA: Information Science Publishing.

[12] Forret, M., Khoo, E. and Cowie, B. (2006). New Wine or New Bottles: What's New about Online Teaching? In: Figueiredo, A. D. \& Afonso A.P. eds., Managing Learning in Virtual Setting: the role of context (p. 253-273). Hershey PA: Information Science Publishing.

[13] Milhauser, K.L. (2006). The Voice of the Online Learner. In: Figueiredo, A. D. \& Afonso A.P. (eds.), Managing Learning in Virtual Setting: the role of context (p. 219-235). Hershey PA: Information Science Publishing.

[14] Penco, C. (1999). Objective and Cognitive Context. In P. Bouquet et al. (eds.), CONTEXT'99 (p. 270-283). Lecture Notes in Artificial Intelligence, 1688, Springer.

[15] Ricoeur, P. (2005). Hermeneutics and the human sciences. Edited and translated by J.B. Thompson ( $17^{\text {th }}$ edition). Cambridge: Cambridge University Press.

[16] Rowe, J. P., Mequiggan, S. W., Mott, B. W. and Lester, J. C. (2007). Motivation in Narrative-Centered Learning Environments. Proceedings of the Workshop on Narrative Learning Environments at the $13^{\text {th }}$ AIED Conference. Marina del Rey, CA, July 2007, p. 40-49.

[17] Shank, R. C. (2000). Tell Me a Story: Narrative and Intelligence, $3^{\text {rd }}$ printing, Northwestern University Press, Evanston, IL.

[18] Sutherland, L. (2002). Developing problem solving expertise: the impact of instruction in a question analysis strategy, Learning and Instruction, 12, 155-187 